\title{
Description of a new gall-inducing species of Aprostocetus (Hymenoptera: Eulophidae) on Melilotus indicus from Southern Italy
}

\author{
G. Viggiani, ${ }^{1}$ R. Monaco² \\ ${ }^{1}$ Laboratorio di Lotta biologica - Dipartimento di Agraria, Università degli Studi di Napoli Federico II; \\ ${ }^{2}$ Dipartimento Scienze del Suolo, della Pianta e degli Alimenti, Università degli Studi di Bari Aldo \\ Moro, Italy
}

\begin{abstract}
Aprostocetus monacoi Viggiani (Hymenoptera: Eulophidae, Tetrastichinae) is described from stem galls in Melilotus indicus (Fabaceae) from Italy. It is the second native European species of Tetrastichinae known as gall inducer.
\end{abstract}

\section{Introduction}

Several decades ago (September 1973) one of us (Monaco, 1976) collected galls on stems of Melilotus indicus (L.) All. in the Bari area (Apulia), and maintained them under laboratory conditions over the winter. In March 1974, two species of Chalcidoidea emerged from these galls, an Aprostocetus sp. (Hymenoptera: Eulophidae) (as Tetrastichus sp. in Monaco, 1976), supposed to be the gall inducer, and the parasitoid Macroneura vesicularis (Retzius) (Hymenoptera: Eupelmidae). Additional galls from the same host plant were collected in 2001 and 2009; from which many chalcidoids emerged. The most

Correspondence: Gennaro Viggiani, Laboratorio di Lotta biologica Dipartimento di Agraria, Università degli Studi di Napoli Federico II, via Università 133,80055 Portici (NA), Italy.

Tel.: +39.081.2539003 - Fax: +39.081 .7755872 .

E-mail: genviggi@unina.it

Key words: European, phytophagous, tetrastichine.

Acknowledgements: the authors are grateful to John LaSalle, CSIRO Entomology, Canberra, Australia, for his suggestions and comments on the manuscript.

Received for publication: 26 June 2013.

Revision received: 20 November 2013.

Accepted for publication: 20 November 2013.

(C) Copyright G. Viggiani and R. Monaco, 2014

Licensee PAGEPress, Italy

Journal of Entomological and Acarological Research 2014; 46:1782

doi:10.4081/jear.2014.1782

This article is distributed under the terms of the Creative Commons Attribution Noncommercial License (by-nc 3.0) which permits any noncommercial use, distribution, and reproduction in any medium, provided the original author(s) and source are credited. abundant was the Tetrastichinae (Hymenoptera: Eulophidae) in this paper described as a new species of Aprostocetus.

\section{Materials and methods}

The material studied was obtained from stem galls in $M$. indicus collected in the Bari area (Southern Italy) during autumn of 2008 and maintained under laboratory conditions. Some adults that emerged in March 2009 were mounted on card-points and others dissected and mounted in Canada balsam phenol.

Abbreviations and terminology are as used by Graham $(1987,1991)$ and Gibson (1997).

\section{Aprostocetus monacoi Viggiani n. sp.}

FEMALE (Figure 1). Body black without metallic reflections; legs black, except distal third of the femur, fore tibia, base and distal quarter of femur and tibia of middle and hind legs which are yellow; tarsi brown yellow, with lighter basitarsus. Wings hyalin; venation yellow brown. Length: 1.6-2.0 mm (average: 1.75; standard deviation: \pm 0.109 ; $\mathrm{n}=16$ ).

Head slightly wider than high; vertex with rather shallow sutures around ocelli and sulcus from lateral ocellus to internal margin of eye; frons with median carina; subantennal groove on supraclypeal area; POL twice 00L; face with scattered short setae; malar space as long as height of eye; malar sulcus straight, without a fovea; anterior margin of clypeus bidentate. Mandibles with three teeth, the external one much pronounced. Maxillary and labial palpi one-segmented.

Antenna (Figure 2A) inserted into torulus above the level of the orbital margin; radicula subquadrate; scape elongate, about four times as long as wide; pedicel a little shorter than half scape length; 3 anelli (Figure 2B); F1 wider than long (less than twice), without linear sensilla but with rather short setae as on the subsequent segments, in one or two rows; F2-F3-F4 subequal, about twice as long as wide, with linear sensilla; club 3-segmented, 1.9 times as long as the preceding funicular segment, $\mathrm{C} 1$ cup-shaped and as long as wide, C2 slight shorter than C1, C3 conical, a trifle shorter than C2 and with a short terminal spine and apical seta.

Mesosoma a little shorter than metasoma (8:10), moderately arcuate; pronotum short, 4.5 times broader than long, with very fine engraved reticulation and scattered short setae; mid lobe of mesoscutum about 1.5 times as long as scutellum, with median line, and with a row of 4-5 adnotaular setae; scutellum as long as broad, with submedian lines nearer sublateral lines than each other, first pair of setae inserted at the middle of the sclerite and about as long as the second pair; mid lobe of mesoscutum and scutellum with a very weak reticulation with subpolygonal cells; dorsellum (Figure 2C) not divided, 2.3 
times wider than long; propodeum (Figure 2C) medially as long as dorsellum, with a weak median carina and raised sculpture as on other mesosoma sclerites, spiracles rather large with margin almost touching metanotum and callus with 7-8 short setae.

Fore wing (Figure 2D) 2.2 as long as wide; costal cell length slightly shorter than marginal vein, with 1-2 lines of setae; parastigma as long as stigmal vein; marginal vein 3 times as long as stigmal vein, gradually decreasing in breadth from base to distal end; postmarginal vein 0.5 as long as stigmal vein; speculum extending behind parastigma; subcubital line of setae starting at level of speculum end; fringe short, maximum length as one third of stigmal vein; discal ciliation rather dense. Hind wing about 4 times as long as broad, apically pointed. Legs with fore tarsus around 0.8 as long as the corresponding tibia, with basitarsus as long as third tarsomere; middle and hind tarsus 0.6 as long as tibia with the same ratio among tarsomeres of the fore leg; spur of the middle tibiae slightly longer than basitarsomere.

Gaster ovate, 1.2 longer than mesosoma, around 1.6 as long as wide; with a short, subtrapeziodal transverse petiole, four times as broad as long; tergites with a weak engraved sculpture as on several sclerites of the body; each cercus with a seta about 1.3 times as long as the other setae. Ovipositor rather short, not extruded, around 1.9 as long as fore tibia, with third valvula 5 times as long as broad and 0.2 as long as the entire ovipositor length. Hypopygium (Figure 2E) with distal margin reaching the distal third of the gaster, two-lobed and with a row of 4-5 setae in proximity of their distal margin.

MALE. Colour and most morphological characters similar to female. Body length: 1.3-1.9 mm (average: 1.61; standard deviation: $\pm 0.186 ; n=7$ ). Antenna (Figure $3 \mathrm{~A}$ ) with scape about 2.8 times as long as wide, 2 times as long as pedicel, with ventral plaque placed along its distal half and occupying around 0.37 length of scape; 3 discoidal anelli (Figure $3 \mathrm{~B}$ ); funicle 4-segmented, F1-F4 subequal, longer than broad and enlarged proximal to their base, where a whorl of long setae is inserted; length increases from F1 to F4, the latter 2.7 times as long as broad; each funicular segment with linear sensoria; setae of whorl on F1-F2-F3 and F4 reaching respectively the proximal part of F3, F4, C1, C2; clava twice as long as F4, not broader than the preceding funicular segments; $\mathrm{C} 1$ and $\mathrm{C} 2$ with a whorl of long setae reaching or overtaking the apex of antenna; C3 with a short apical spine; all clava segments with linear sensoria. Mid lobe of mesoscutum with a row of three adnotaular setae. Gaster 1.6 times as long as mesosoma, 2.1 times as long as wide. Genitalia ovate (Figure 3C), length 0.036 $\mathrm{mm}$, phallobase 3.5 times as long as wide; digitus with one spine.

\section{Type material}

HOLOTYPE : ITALY, Bari, 23.III.2009, ex gall in stem of Melilotus indicus, coll. R. Monaco; on card-point.

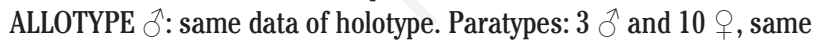
data as holotype.

ADDITIONAL MATERIAL: 10 slides with dissected parts of females and males.

Holotype, allotype and 5 paratypes will be deposited in the entomological collection of the Dipartimento di Agraria dell'Università degli Studi di Napoli Federico II; 2 female paratypes in the Natural History Museum, London.

ETYMOLOGY. The name refers to Raffaele Monaco who discovered the new species.

BIOLOGY. According to the observations carried out by one of us (R.M) A. monacoi emerges from overwintering galls in stems of $M$. indicus during spring. The female oviposits in the new stems, at a distance of 3-4 cm from their apex. After the deposition of several eggs (even several tens) the tissues of the host plant develop in conspicuous oval or spindle-shaped galls, more rarely spherical (Figure 4A). Their dimensions are variable, but the most common spindle-shaped galls measure on average $3-4 \mathrm{~cm}$ in length and $0.5-0.8 \mathrm{~cm}$ in breadth; the corresponding uninfested stem diameter is on average $3-4 \mathrm{~mm}$. The galls develop in April-May and reach maturity in June-July. Then they become dry and overwinter. The larvae develop individually in cavities produced in the gall walls (Figure $4 \mathrm{~B}$ and $\mathrm{C}$ ). The galls are not detachable from the stems. Females and males emerge from the same gall. The sex ratio was in favour of the females (3.85:1). Females of $A$. monacoi oviposit in young stems of $M$. indicus, but not on M. sulcatus Desf.

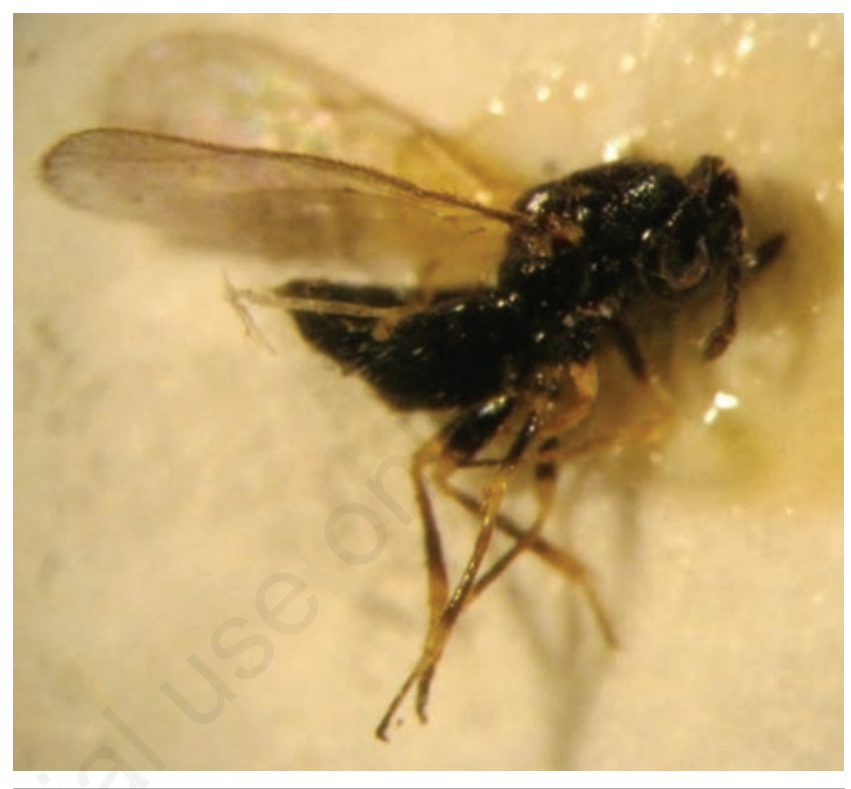

Figure 1. Aprostocetus monacoi Viggiani n. sp., female.
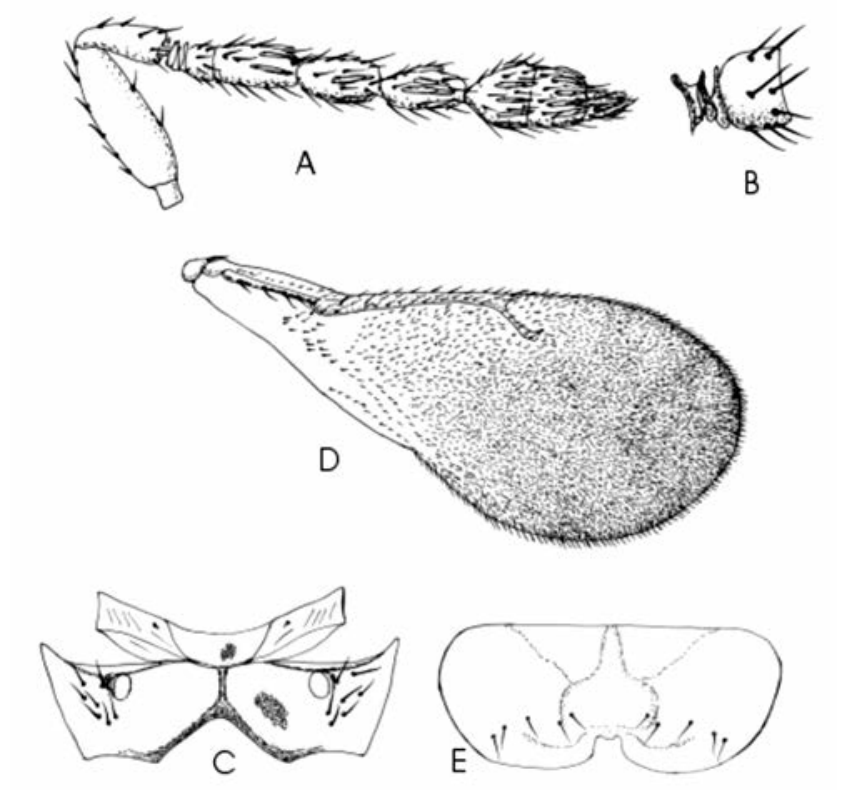

Figure 2. A) Aprostocetus monacoi Viggiani n. sp., female: antenna; B) Aprostocetus monacoi Viggiani n. sp., female: antennal anelli and first funicular segment; C) Aprostocetus monacoi Viggiani n. sp., female: metanotum and propodeum; D) Aprostocetus monacoi Viggiani n. sp., female: fore wing; E) Aprostocetus monacoi Viggiani n. sp., female: hypopygium. 

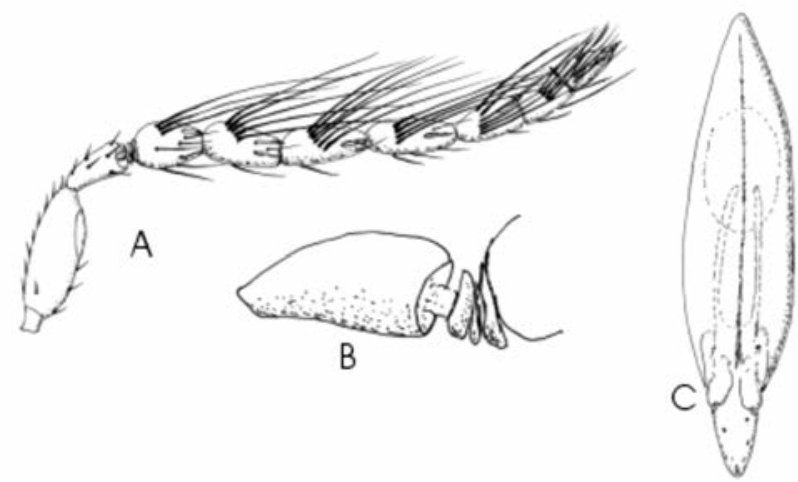

Figure 3. A) Aprostocetus monacoi Viggiani n. sp., male: antenna; B) Aprostocetus monacoi Viggiani n. sp., male: pedicel and antennal anelli; C) Aprostocetus monacoi Viggiani n. sp., male: genitalia.

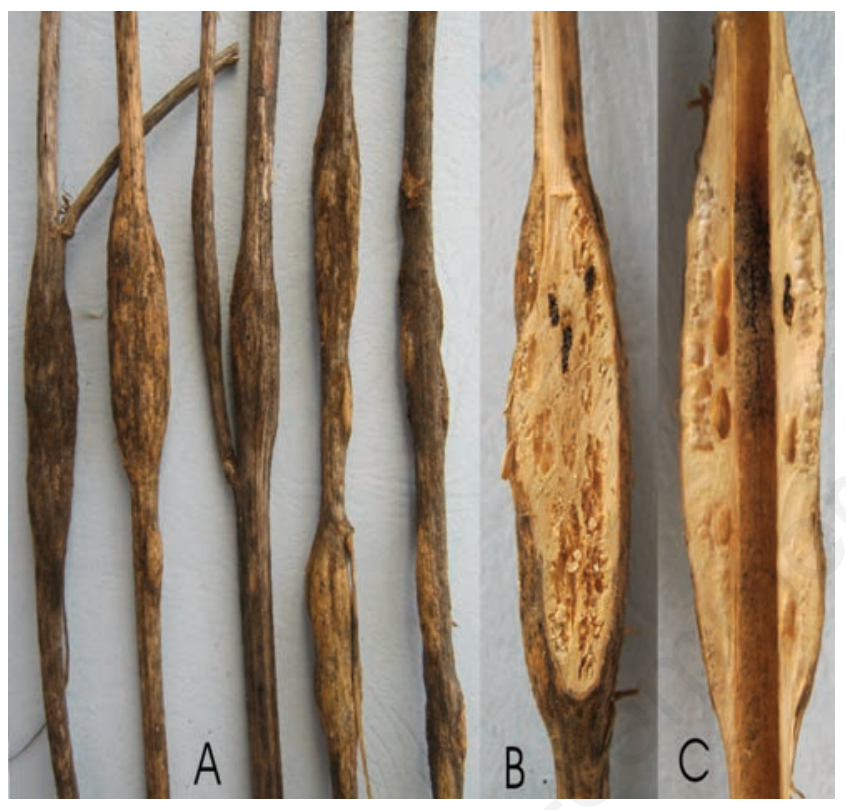

Figure 4. A) Dried galls in Melilotus indicus stems; B) Longitudinal submedian section of a dried gall in Melilotus indicus stem; C) Longitudinal median section of a dried gall in Melilotus indicus stem.

\section{Results and conclusions}

The new species is included in the genus Aprostocetus Westwood, subgenus Aprostocetus, according to generic keys to Tetrastichinae for Europe (Graham, 1987, 1991), and North America (LaSalle, 1994; Schauff et al., 1997). In the key to the European species of subgenus Aprostocetus, A. monacoi would key to the elongatus-group (couplets 46 ) based on having a four-segmented funicle. This is a difficult character, as it is not always clear as to the distinction between an enlarged apical anellus, and a short first funicule segment. In A. monacoi the first funicle segment is distinctly larger than an anellus, slightly wider than long, with distinct stout setae, although lacking longitudinal sensilla. Within Graham's key, A. monacoi would key to near A. collega based on lacking a triangular fovea in the malar sulcus beneath the eye, and having the gaster distinctly less than twice as long as head plus thorax. A. collega differs from A. monacoi in having the body usually black and yellow, a longer F2, mid lobe of mesoscutum without a median line and longer gaster.

A. monacoi is also easily distinguishable from the first known native European tetrastichine Aprostocetus (Argandia) gallicola Nieves-Aldrey \& Askew (2011) which has yellow tibiae, particularly striking sutures around the ocelli, mandible with 2 teeth, antennal funicle 3-segmented, mid lobe of mesoscutum without median line and a swollen base of the fore wing marginal vein. The biology of $A$. gallicola, which is a gall inducer in Hedysarum boveanum, is very similar to that of $A$. monacoi, but the gall structure seems rather different, having a large internal cavity where the larvae evolve gregariously.

A species of phytophagous Tetrastichus, erroneously determined as venustus Gahan and then recognized as an undetermined species of Aprostocetus (La Salle, 1994), as been recorded from swelling on stems of Melilotus in North America (Teitelbaum \& Black, 1954).

The only other species of Aprostocetus known to be a gall inducer is A. colliguayae, which is a gall inducer on Colliguaja odorifera Molina (Euphorbiaceae) in Chile (La Salle, 2005).

\section{References}

GIBSON G.A.P., 1997 - Morphology and terminology. In: GIBSON G.A.P., HUBER T., WOOLLEY G.B. (Eds), Annotated keys to the genera of Nearctcic Chalcidoidea (Hymenoptera). - NRC Research Press, Ottawa.

GRAHAM M.W.R.deV., 1987 - A reclassification of the European Tetrastichinae (Hymenoptera: Eulophidae), with a revision of certain genera. - Bull. British Museum Nat. Hist. Entomol. Ser. 55: 1-392.

GRAHAM M.W.R.deV., 1991 - A reclassification of the European Tetrastichinae (Hymenoptera: Eulophidae): revision of the remaining genera. - Memoirs Am. Entomol. Inst. 49: 1-322.

LA SALLE J., 1994 - North American genera of Tetrastichinae (Hymenoptera: Eulophidae). - J. Nat. Hist. 28: 109-236.

LA SALLE J., 2005 - Biology of gall inducers and evolution of gall induction in Chalcidoidea (Hymenoptera: Eulophidae, Eurytomidae, Pteromalidae, Tanaostigmatidae, Torymidae). In: RAMAN A., SCHAEFER C.W., WITHERS T.M. (Eds), Biology, ecology, and evolution of gall-inducing arthropods. - Science Publishers, Inc., Enfield, New Hampshire: 507-537.

MONACO R., 1976 - Descrizione del maschio e di una femmina teratologica di Macroneura vesicularis (Retzius) (Hym. Chalcidoidea). Entomologica 12: 135-141.

NIEVES-ALDREY J.L., ASKEW R., 2011 - Two new species of Tetrastichinae (Hymenoptera: Eulophidae) from Spain, the first known native European gall inducing tetrastichine and its parasitoid. - Ann. Soc. Entomol. Fr. (n. s.) 47: 154-161.

SCHAUFF M.E., LA SALLE J., COOTE L.D., 1997 - Chapter 10. Eulophidae. In: GIBSON G.A.P., HUBER T., WOOLLEY G.B. (Eds), Annotated keys to the genera of Nearctcic Chalcidoidea (Hymenoptera). - NRC Research Press, Ottawa.

TEITELBAUM S.S., BLACK L.M., 1954 - The effect of a phytophagous species of Tetrastichus, new to the United States, on sweet clover infected with wound-tumor virus. - Phytopathology 54: 548-550. 